\title{
CAST METAL FLOW ANALYSIS OF INTERMEDIATE FLANGE
}

\author{
Hemalatha.S ${ }^{1}$, N.Ramesha $\mathbf{R}^{2}$ \\ ${ }^{1}$ Student. Dept. of PG studies, Govt. Tool Room \& Training centre, Mysore-570016 \\ ${ }^{2}$ Lecturer. Dept. of PG studies, Govt. Tool Room \& Training centre, Mysore-570016
}

\begin{abstract}
The production of aluminium alloy die castings has been seeing a continuous increase to answer the strong demand by the automotive industry for higher strength and lighter weight. The die castings for automotives are required of not only high quality as of course but also thin walls and a high dimensional precision, thus it is essential to provide advanced casting technologies for the manufacturing of these castings. The main challenge in die casting is design and manufacturing of die. Integration of design and analysis yields to better results. Die casting is often encountered with many problems, few of such problems are blowholes, improper filling, scratch marks, weld lines, cracks, cold shut, porosity, blisters, ejector pin marks, etc. usually these defects are caused due to improper design of dies, or due to incorrect parameters such as injection pressure, cycle time, cooling circuits and other such parameters $n$ order to eliminate such defects a set of analysis has to be carried to ensure that design and other parameters are safe and efficient. Through analysis is carried to understand how the molten metal behaves inside the dies once it is injected, a clear picture about how the molten metal gets solidified is obtained during analysis. Any defects if present can be studied by analysing the results of analysis. In this paper Adestefan analysis software is used for analysis purpose, the flow of molten metal inside the impression was studied and changes to be made to the design were analysed. Behaviour of molten metal at different stages of time such as temperature variations, pressure variations is analysed.
\end{abstract}

Keywords: Flow analysis, solidification, aluminium die casting, , temperature analysis, die casting, Adestefan.

\section{INTRODUCTION}

Die casting is a versatile process in which molten metal is poured in to dies which form the shape and size of the component. The production of aluminium alloy die castings has been seeing a continuous increase to answer the strong demand by the automotive industry for higher strength and lighter weight. The die castings for auto motives are required of not only high quality as of course but also thin walls and a high dimensional precision, thus it is essential to provide advanced casting technologies for the manufacturing of these castings. The use of simulation programs saves time and reduces the costs of the casting system design. At the same time it is possible to meet stringent product quality. Simulation can make a casting system optimal: it enables the producing of sound, high-quality castings with fewer experiments. Furthermore environmental savings and economical use of materials can be achieved when the number of test castings is reduced. Foundries use now widely simulation codes that are based on a thermal conduction model where thermal conduction in the melt and liberation of latent heat during solidification are considered. Fluid flow simulations are less used. However, e.g. aluminium die casting is so complicated in which flow analysis plays a crucial role in the mould filling process due to the high velocity of the liquid metal. Inertia effects may cause splashing, jetting or undesirable filling of the metal flow into mould cavity. When considering complex parts, the accurate prediction of mould filling behaviour using empirical knowledge is nearly impossible. Analysis is an important part of die casting. It shows virtual activity inside the die. Starting from air movement to molten metal flow. With the advancement in computer an effort is made to study the defects in the die casting as a consequence of physical phenomenon that are involved. A detailed modelling with improved description of physical processes has become more realistic and straight forward approach.

This paper details about Aluminium ADC12 which is the casting material, having shrinkage of $01.006 \%$, its melting temperature range is $640^{\circ} \mathrm{Cto} 670^{\circ} \mathrm{C}$. Density of the $\mathrm{ADC}$ is $2.71 \mathrm{gm} / \mathrm{cm} 3$. Aluminium ADC12 must be melted to $640^{\circ} \mathrm{Cto}$ $670^{\circ} \mathrm{C}$ as it gives optimum results. If it is heated beyond $680^{\circ} \mathrm{C}$ aluminium gets oxidized. Below $640^{\circ} \mathrm{c}$ proper filling is not possible.

The die material HDS H13 (hot die steel) is heat treated to 53HRC. HDS obtains maximum hardness when heat treated to 53HRC. A premium hot work steel with very good high temperature properties. Can be hardened \& tempered to 58HRC giving an outstanding hot wear resistance. 


\section{UNDERSTANDING AND OPTIMIZING PROCESS THROUGH SIMULATION}

\section{COMPROMISES OF}

$>$ Realistic and detailed mapping of all process steps

$>$ Optimization of the filling process and the cooling of the melt in the shot sleeve

$>$ Reduction of die costs by evaluating the die design regarding heat-checking and lifetime

$>$ Reduction of cycle times through optimization of heating and cooling channels

$>$ Reduction of quality costs by avoiding casting defects that arrive from cold laps, turbulence, air entrapment, gas porosity, and shrinkage

$>$ Time savings and a robust layout of ingates, runners and vents, vacuum channels and overflows

$>$ Early and reliable decisions through quantitative predictions of component or tool properties

$>$ Reduction of production risks by using a high pressure die casting calculator for the rigging layout

$>$ Minimization of straightening costs caused by modifying cooling conditions, quenching, trimming and heat treatment.

\section{SIMULATION AND ANALYSIS METHOD:}

The use of simulation programs saves time and reduces the costs of the casting system design. At the same time it is possible to meet stringent product quality. Simulation can make a casting system optimal: it enables the producing of sound, high-quality castings with fewer experiments. Furthermore environmental savings and economical use of materials can be achieved when the number of test castings is reduced.

In most of the industrial nations, about $70 \%$ of the die cast parts go to the automotive industry. Aluminium die castings are gaining importance in the production of lightweight vehicle bodies, as for example used in new model Audi cars. Therefore, it is even more vital today that these castings can be produced with the high quality methods. In this context the simulation is becoming more essential in the designing process.

Analysis of the part is done using ADESTEFAN software. Analysis is done in order to determine the behaviour of molten metal inside the die. The flow of molten metal plays an important role in filling up of the component, the direction of flow shows the proper filling in dies(5), which gives an idea about possibilities of generation of blowholes due to porosity which intern helps us to decide the placement of air vents, chill vents, cold wells. Solidification analysis helps us understand how the molten metal gets solidified within the dies, which area solidifies first and which area solidifies at last, this result helps us to alter the gating, runner arrangements. Temperature analysis helps us in designing cooling channels and cooling circuits. This analysis result helps in optimizing design and various process parameters. To obtain optimum results in this software, the number of input data must be provided correctly.

The main inputs to be provided for analysis are

$>$ Thermo physical properties such as density, specific heat, thermal conductivity, die material, and temperatures.

$>$ Boundary conditions such as die material heat transfer coefficient, feed aids including chills air vents.

$>$ Process parameters such as poring rate and temperature.

ADESTEFAN utilizes computer aided design (CAD) files for analysis in STL format. ADESTEFAN based on finite element method (FEM) technology is able to predict flow of molten metal, temperature, and pressure variations, air movement, residual stresses and deformations. This software incorporates CAD data with FEM techniques to quickly and easily enable a virtual "what if" design before die construction. It also enables to optimize process parameters and die design.

\subsection{Fluid Flow Analysis}

Fluid flow analysis simulations are done to attain better casting system design in HPDC castings. Flow analysis is used to determine the size and location of the gate as well as proper runner system design for ensuring a complete and balanced filling of the part. Flow analysis in High Pressure Die Casting process ensures the minimum air entrapment during the prefilling phase. Flow simulations should be used in many instances, e.g. in aluminium die casting, which is particularly because flow momentum plays a crucial role in the mould filling process due the high velocity of the liquid metal. Inertia effects may cause splashing, jetting or undesirable filling of the metal flow into mould cavity. When considering complex parts, the accurate prediction of mould filling behaviour using only empirical knowledge is virtually impossible. It is commonly accepted that shrinkage and gas are two major causes of porosity. The shrinkage porosity is associated with the hot spot in the casting. The gas porosity has four different reasons: 1) Trapped air that is entrained in the injection system and cavity: 2) Gas generated from burned lubricants; 3) Gas generated from water that may be in cavity and 4) Hydrogen gas. The gas. porosity due to the trapped air is an unwanted byproduct of relatively high velocity injection method used. In high pressure die casting, some efforts have been made to reduce air entrapment by the modification of conventional injection shot profile taking advantages of the development of advanced and reliable control systems. 


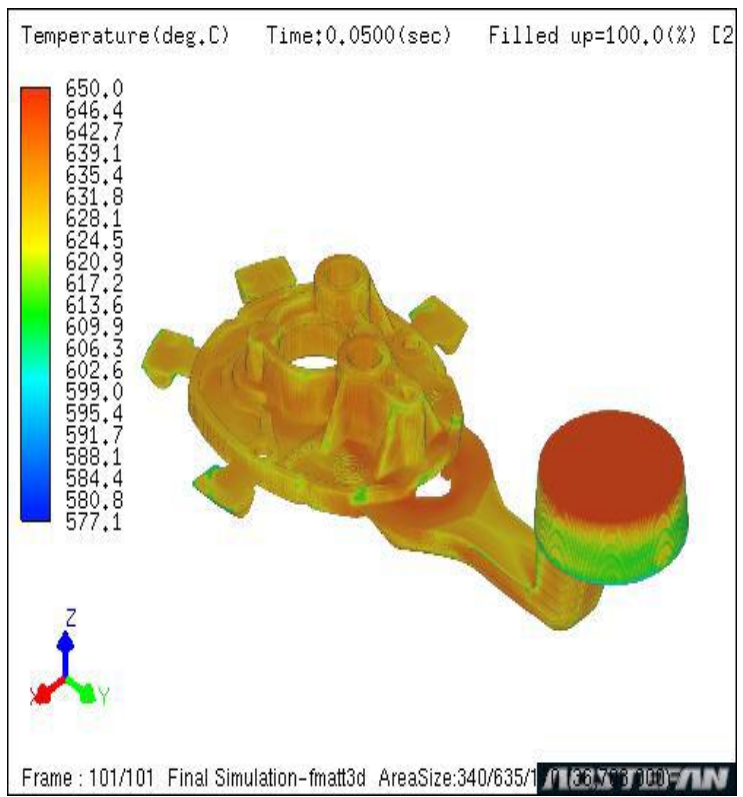

Fig 1: Shows uniform temperature distribution during flow analysis

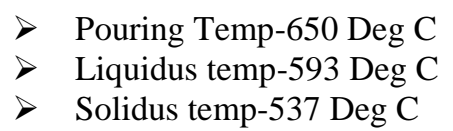

Observation-During the filling of the molten metal into the cavity, there is no temperature drop below the solidus temperature and the temperature distribution is varying between 625 Deg C to 600 Deg C

\subsection{Air Entrapment}

Analysis was carried to study how the air inside the impression will flow when the molten metal is injected into the die. This is one of the important factors to be taken care of, if air is present inside the die it mixes with the molten metal and forms the weaker portion of the component. The air present inside the dies also generates blow holes, porosity. This leads to a weak component. Die casted components usually finds its scope in places which are subjected to high temperatures, pressures. This indeed faces high thermal stress. Components with blow holes and porosity, often fail in these situations. A thorough analysis of part was made to check how the air travels out during the injection stoke. Results show that air is being pulled out by air vents, and there is no mixing of air and molten metal. Hence component is free from porosity and blow holes.

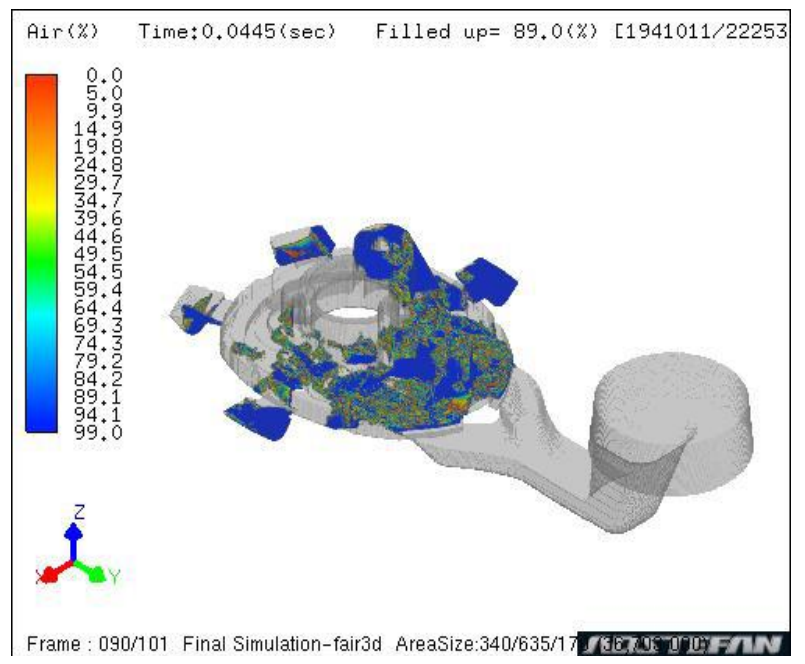

Fig 2- Air entrapment result

Fig 1 shows the air being pushed out as the molten metal advances in to die cavity.

$>$ Blue colour -air in the component

$>$ Transparent colour-complete liquid metal

$>$ Green colour -mixture of liquid metal and air

Observation: Air entrapment defects is observed in the component as shown above. Location of flow offs can be reconsidered

\subsection{Solidification Analysis}

Molten metal inside the die gets solidified soon after it is injected into the die. Die has to be allowed in closed position for some time to allow this solidification. If the component is ejected before solidification, the component will not be proper and it will not attain its geometrical features.

\subsubsection{Solidification Analysis (Progressive Analysis)}

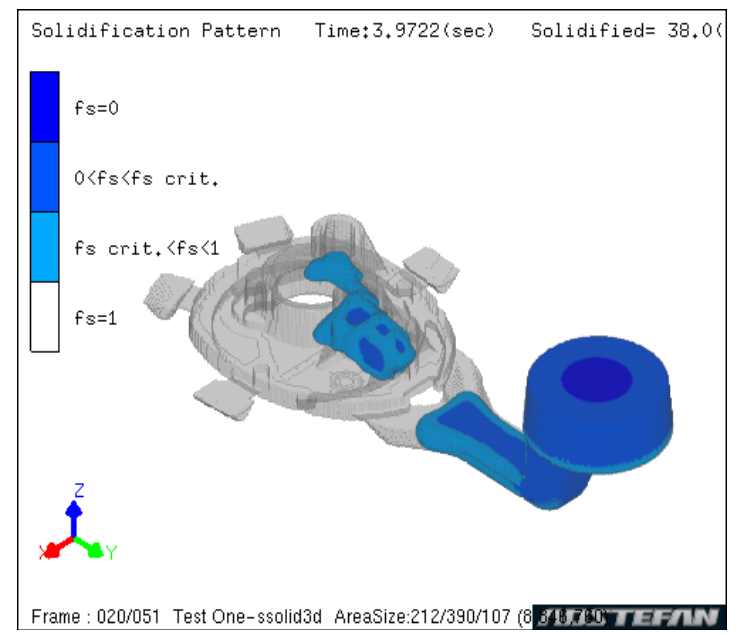

Fig 3 Progressive solidification 
Observation: The picture shows the final stage of solidification. The highlighted area of the casting is the last to solidify and these regions may lead to shrinkage porosity defects.

Fig 3shows the temperature of the molten metal when it is solidifying. It is clear from the fig 2.3 that the runner, gates and overflows are solidified before the component metal is being solidified. In order to obtain an optimum design, first the runners and gates must solidify before the metal which forms the component solidifies. If the component solidifies before the gate then due to pressure difference the molten metal inside the component area will flow back to runner and sprue resulting in non uniform packing of the component.

\subsubsection{Solidification Analysis (Shrinkage Porosity)}

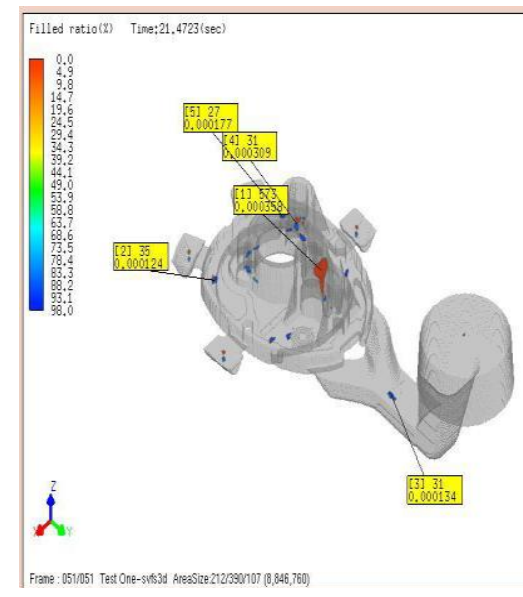

DESTERT

Fig 4 Shrinkage and porosity analysis

$>$ Pouring Temp-650 Deg C

$>$ Liquidus temp-593 Deg C

$>$ Solidus temp-537 Deg C

Observation: Figure shows the final solidification results and possibility of shrinkage related defects in the highlighted regions along with volume of shrinkage.

\subsection{Temperature Distribution during Component}

\section{Filling.}

Temperature distribution in die casting is also important as it plays a vital role in deciding the quality of castings. The die is preheated to $250^{\circ} \mathrm{c}$ (usually in die casting dies are pre heated from $150^{\circ}$ to $\left.300^{\circ} \mathrm{c}\right)(4)$. Aluminium which is in the form of ingots is melted to around $650^{\circ}-660^{\circ} \mathrm{c}$. and molten metal at around $650^{\circ} \mathrm{c}$ is injected in to the die using plunger (in case of hot chamber molten metal is directly fed into the dies) when the molten metal comes in contact with the dies which is at lower temperatures (around $250^{\circ} \mathrm{c}$ ) tries to cool down due to temperature difference. If the molten metal decreases below liquidious temperature $\left(590^{\circ} \mathrm{c}\right)$ the component will not be filled properly and chances of producing a defected component is high. In case of larger components where surface area is too large and time required for molten metal to reach the last point ( point away from the injection point) is too high, in these situations the molten metal before it reaches the last point may reduce to liquidious temperature hence care must be taken during designing of the dies.

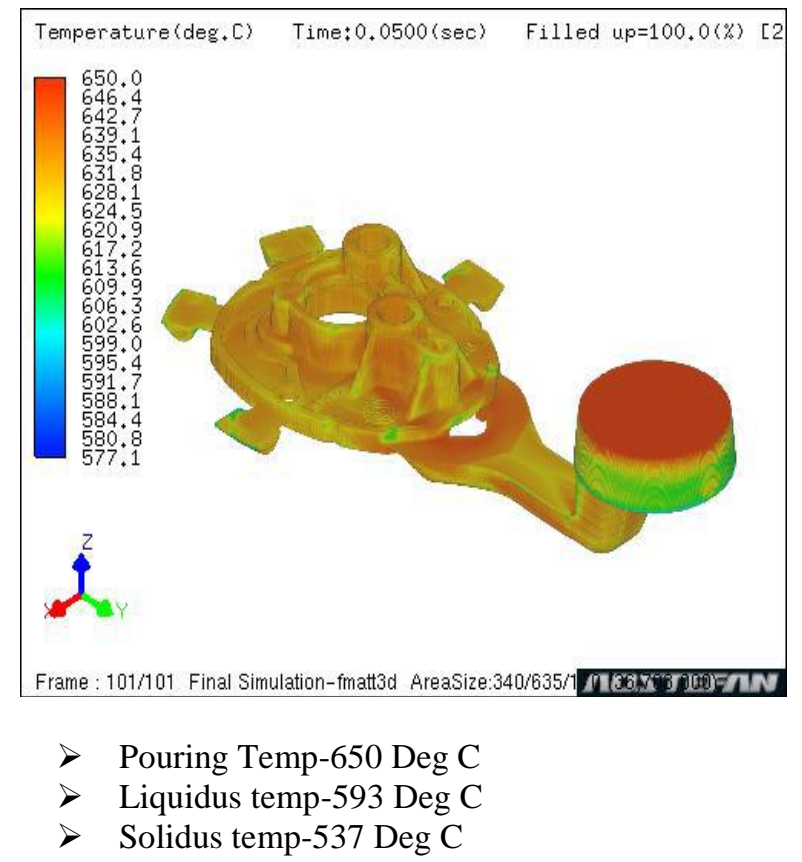

Observation-During the filling of the molten metal into the cavity, there is no temperature drop below the solidus temperature and the temperature distribution is varying between 625 Deg C to 600 Deg C. The above fig 2.4.1 illustrates the temperature of the component when the injection is completed i.e., when the component is completely filled. It shows that temperature is around $650^{\circ} \mathrm{c}$ inside the component. This shows that the component quality will be good.

\section{CONCLUSIONS}

\subsection{Fluid Flow Analysis}

Fluid flow is well progressed as the molten metal temperature after drop is still above the solidus temperature. But better location of flow offs will help easy evacuation of air.

\subsubsection{Solidification}

Solidification process is well progressed as less number of discontinuities are observed. Thicker section is prone to shrinkage.

* Component is free from air entrapments. Overflows, chill vents design are best situated. Runner design and gate location and design are best situated. 
Overflows will get sealed before the molten metal inside the impression which forms the shape of the component solidifies.

* Injection of molten metal at $640-670^{\circ} \mathrm{c}$ results in proper filling and solidification of molten metal.

\section{REFERENCES}

[1] D. G. Eskin, Suyitno and L. Katgerman: Progress Mater. Sci. 49 (2004) 629-711.

[2] H. F. Bishop, C. G. Ackerlind and W. S. Pellini: AFS Trans. 60 (1952) 818-833.

[3] J. Vero: Met. Industry 48 (1936) 431-455.

[4] E. Niyama: Japan-US Joint Seminar on Solidification of Metals and Alloys, Tokyo (Japan Society for Promotion of Science) (1977) pp. 271-282.

[5] H. Fredriksson, M. Haddad-Sabzevar, K. Hansson and J. Kron: Mater. Sci. Technol. 21 (2005) 521-529. 